\title{
Cyclosporin and the clinical investigator
}

To the Editor - The February issue Commentary by Drs. Flowers and Melmon on the role of clinical investigators in pharmaceutical innovation' included some discussion of cyclosponin A and adds a new item to the long list of false statements on the discovery and development of this drug. Some of the untrue and misleading previous accounts on the history of cyclosporin have already been examined ${ }^{2}$.

Work of Calne's group with cyclosporin certainly was very important for the development of this immunosuppressant. However, Flowers' and Melmon's conclusion "that Calne and White originated the idea ... for the development of cyclosporin for prevention of allograft rejection" and the conjecture "probably ... they [researchers of Sandoz] did not conceive of the indication [graft rejection] themselves ..." are clearly incorrect. To realize that, it will suffice to consult the Discussion in our first full paper on the immunosuppressive effects of cyclosporin ${ }^{3}$. There, among the possible indications, organ transplantation is listed in the first place. This publication also reports the results of our transplantation experiments (skin and bone marrow) with cyclosporin in animals. The manuscript of this paper was submitted in January 1976, several months before cyclosporin became known to Calne and White. In addition, there are documents which prove that my then coworker S. Lazary and I had organ transplantation already in mind when, in June 1967, we proposed further development of the (preclinical) predecessor of cyclosporin (ovalicin, another immunosuppressive fungus product without bone marrow toxicity ${ }^{*}$. Organ transplantation, particularly that of bone marrow, had caught our attention as well because we had been working since the 1950's in cancer chemotherapy, incidentally with compounds which also showed immunosuppressive activity.

Cyclosporin differs from the compounds which emerged from the brilliant work of Hitchings and Elion at Burroughs Wellcome in so far as it was not the result of systematic biochemical research, but was picked up in a screening which was designed to detect, among others, immunosuppressive effects ${ }^{2}$. Another difference between the group at Burroughs Wellcome and ours at Sandoz may have contributed to an earlier realization of possible clinical indications of our compounds: many researchers in the (preclinical) Pharmacology Department of Sandoz, including myself and my superiors, were MDs. Therefore, we were perhaps more inclined to constantly keep in mind possible clinical applications of our research than the people in the Biochemistry Department at Burroughs Wellcome who apparently had a more basic research-oriented approach.

\section{HARTMANN F. STÄHELIN \\ Hardstr. 80 \\ $\mathrm{CH}-4052$ Basel, Switzerland}

Flowers and Melmon reply - We appreciate Dr. Stähelin's letter and recognize that his review ${ }^{2}$ and comments reflect a detailed, firstperson account of the discovery and development of cyclosporin as it appeared within Sandoz. We did not study this complex setting but our data do not conflict with his recounting of Calne's role in the development of cyclosporin.

Our intention was to demonstrate that Calne and White's becoming clinical champions was integral to the transfer of the drug to a human application. Rather than focusing on who did the first transplantation experiment using cyclosporin in animals, we hoped to draw attention to the fact that Calne and White recognized the value of using cyclosporin as an immunosuppressant in the context of transplantation and initiated collaboration with Sandoz. One might have thought that Sandoz would have recognized the benefit of collaborating with an outside researcher because of Calne's proven track record for promoting the successful development of an immunosuppressant (azathioprine) in dog renal transplantations experiments and later in man, and his continued research in this area. However Stähelin's comments suggest that not only did Sandoz fail to recognize the value of external clinicians for promoting drug development, but the company also underestimated the contributions of its own clinical and fundamental researchers.

\section{ChrISTOPHFR R. Flowers ${ }^{1} \&$}

KENNETH L. MEL.MON ${ }^{2}$

'Research Assistant, Divisions of Medical Information Sciences and Clinical Pharmacology, Stanford University School of Medicine Stanford, Califormia 94035, USA

${ }^{2}$ Associate Dean for Postgraduate Medical Education and Professor of Medicine and Moleuclar Pharmacology, Stanford University School of Medicine, Stanford, California 94035, USA

1. Flowers, C.R. \& Melmon, K.L. Clinical investigators as critical determinants in pharmaceutical innovation. Noture Medicine 3,136-143 (1997)

2. Stähelin, H.F. The history of cyclosporin A (Sandim muneR) revisited: another point of view. Experientio 52 S-13 (1996).

3. Bored, J.F., Feurer, C., Gubler, H.U. \& Stähelin, H. Biological effects of cyclosporin A: a new antily phocytic agent. Agents \& Actions 6,468-475 (1976).

4. Lazary, S. \& Stähelin, H. Immunosuppressive and specific antimitotic effects of ovalicin. Experientio 24 1171-1173 (1968).

5. Stähelin, H.F. \& von Wartburg, A. The chemical and biological route from podophyllotoxin glucoside to etoposide: ninth Cain Memorial Award Lecture. Concer Res. 51, 5-15 (1991).

\section{Importance of anti-HIV-1 antibodies}

To the editor - We were surprised to read the recent letter by Parren, Burton and Sattenau concerning the importance or otherwise of anti-HIV-1 antibodies'. In it they suggest that "the antibody response to HIV-1 is not directed to the virus, but instead is directed to viral debris", based upon what is presented as a well known fact - that anti-HIV-1 antibody is unable to clear or control HIV-1 infection in any but the most rare and exceptional examples. Some twelve years ago we showed that while indeed both healthy HIV-1-infected and AIDS patients had anti-viral antibodies, healthy individuals, and only they, had high levels of antibodies tha' readily neutralized high levels of HIV-1, ir vitro $^{2}$, correlating with well-being, high levels of CD4 T-cells and failure to detec infectious HIV-1 in the plasma ${ }^{3}$. More tc the point, when plasma from healthy in fected individuals was administered tc AIDS patients in trials of passivt imunotherapy, the viremia of the AIDS re. cipients - that is, what would be primary isolates of $\mathrm{HIV}$ - was no longer de. tectable, even by PCR4.

As far as control of infection is con. cerned, we and subsequently various oth. ers have carried out trials of passive 
immunotherapy (PIT) in AIDS patients, some of them double-blind control studies showing significant clinical benefits to the recipients ${ }^{s-s}$. Also, in studies of long term survivors of HIV infection, all survivors have been found to have high levels of neutralizing antibodies ${ }^{9.10}$ sometimes without significant cellular immunity against HIV-infected cells'. We also have evidence to suggest that passive immunotherapy given in the early stages of the diseases, induces long-term clinical remission: we have been monitoring an HIV-positive child in whom PIT was initiated at the age of 3.5 years and who has been receiving plasma at monthly intervals (since August 1993) as the only antiHIV-1 treatment. The child has normal physical and mental development.

We hope this may convince Parren et al. that HIV-1 neutralizing antibodies, far from being unusual, are a normal response in the early stages of infection and that they correlate with and perhaps explain the unusually long (nine years on average) AIDS-free period. The reason that they eventually fail to win the war against the infection is unknown but may be due to: continued viral integration, reproduction and infection of new cells in lymphoid sites inaccessible to antibodies; cell-to-cell transmission of infection; the emergence of neutralizing-resistant mutant viral strains; or infection and destruction of CD4 T-cells, removing the helpers for antibody-producing cells, so depleting and eventually ablating the protective response.

\section{ABRAHAM KaRPaS}

Department of Haematology, Cambridge

University Clinical School, MRC Centre, Hills

Road, Cambridge, CB2 $2 \mathrm{QH} U K$

\section{STEPHEN ASH}

Ealing Hospital, London, UB1 $3 H W$ UK

\section{DOUGLAS BAINBRIDGE}

Royal London Hospital, London, UK

Parren et al. reply - Dr. Karpas and colleagues question our conclusion that the antibody response in HIV-1 infection is elicited by viral debris rather than the virus by quoting examples of the supposed efficacy of antibody in controlling HIV-1 infection. They state that our argument is based on the inability of antibody to clear HIV-1 infection. It is not. It is based on the general observation that anti-HIV antibodies from seropositive donors display high affinities for viral debris (unprocessed gp160 in particular) and poor affinities for native viral envelope oligomer. As a consequence of this, typical anti-HIV antibodies may be rather inefficient against the virus.

The evidence that Karpas et al. put forward for the efficacy of antibodies in controlling HIV-1 infection is unconvincing. First, some of Karpas' methodology may be flawed as has been critically appraised elsewhere ${ }^{2}$. Second, studies relying on clinical benefit $t^{6,7}$ may measure the effects of passively transferred immunoglobulin specific for opportunistic pathogens. Changes in HIV-1 viral loads furthermore were not addressed, but a recent study with a comparable immune globulin preparation indicated no significant effects on viral levels ${ }^{12}$. Moreover, hyperimmune globulin trials in mother-child transmission have recently been discontinued in the US because of lack of clear evidence of efficacy.

Neutralizing antibody responses in long-term non-progressors (LTNP) are somewhat broader and more potent compared with other HIV-1 infected individuals ${ }^{13}$. Although statistically significant, this relationship is not absolute as suggested by Karpas et al., and LTNP are heterogeneous as a group with respect to the magnitude of the viral load and antiviral activity of both cellular and humoral immune responses ${ }^{14}$. The analyses therefore do not immediately imply a causal relationship between the presence of these antibodies and survival. Broader neutralization, for example, could also be the result of the long-term exposure to a greater variety of quasispecies within a constantly changing viral population. A conclusion that can be drawn however is that even in LTNP, except for very few exceptional cases, primary isolate neutralizing antibody serum titers are poor.

Re-examination of the data from passive immunization trials and antibodies in LTNP therefore demonstrate an agreement between in vivo and in vitro studies and indicate a general inefficiency of anti-HIV-1 antibodies against the virus. Finally, we emphatically do not discount that antibodies, either passively introduced or from vaccination, could be effective against HIV-1. Our argument is rather that the quality of these antibodies is a critical factor. Natural infection and subunit vaccination appear to produce very few antibodies of useful anti-viral potency.
PAUL W.H.I. PARREN ${ }^{1}$, QUENTIN J. SATTENAU ${ }^{2} \&$

DENNIS R. BURTON ${ }^{-1}$

'The Scripps Research Institute, Departments of Immunology and Molecular Biology 10550 North Torrey Pines Road (IMM2)

La Jolla CA 92037, USA

Email:burton@scripps.edu

${ }^{2}$ Centre d'Immunologie de Marseille Luminy

Case 906, 13288 Marseille, France

1. Parren, P.W.H.I., Burton, D.R. \& Sattenau, Q.J. HIV-1 antibody - debris or virion? Nature Med. 3, 366 (1997).

2. Karpas, A. et al. Lytic infection by British AIDS virus and the development of rapid cell test for antiviral antibodies. lancet ii, 695 697 (1985).

3. Karpas, A. et al. Effect of passive immunization in patients with acquired immunodeficiency syndrome -related complex and acquired immunodeficiency syndrome. Proc. Nati. Acad. Sci. USA 85, 9234-9237 (1988).

4. Karpas, A. et al. Polymerase chain reaction evidence for immunodeficiency virus-1 neutralization by passive immunization in patients with AIDS and AIDS-related complex. Proc. Natl. Acad. Sci. USA 87, 1195-1199 (1990).

5. Vittecoq, D. et al. Passive immunotherapy in AIDS: a randomized trial of serial human immunodeficiency virus-positive transfusions of plasma rich in p24 antibodies versus transfusions of seronegative plasma. I Inf. Diseases 265, 364-368 (1992)

6. Levy, J. et al. Passive hyperimmune therapy in the treatment of AIDS: Results of a multicenter doubleblind controlled trial. Blood 84, $2130-2135$ (1994).

7. Vittecoq, D. et ai. Passive immunotherapy in AIDS. A double-blind randomized study based on transfusions of plasma rich in anti human immunodeficiency virus 1 antibodies versus transfusions of seronegative plasma. Proc. Natl. Acad. Sci. USA 92, 1195-1199 (1995).

8. Blick, $G$. et al. Passive immunotherapy in advanced HIV infection and therapeutic plasmaphoresis in asymptomatic HIV-positive individuals: A four-year clinical experience. Biother. (in the press).

9. Cao, Y. et ol. Virologic and immunologic characterization of long term survivors of human immunodeficiency virus type 1 infection. N. Engl. I. Med. 332, 201-208 (1995)

10. Pantaleo, G. et al. studies in subjects with long term non-progressive human immunodeficiency virus infection. N. Engl. 1. Med. 332, 209-216 (1995).

11. Jacobson, J.M. et al. Passive Immunotherapy in treatment of advanced human immunodeficiency virus infection - Reply. J. Infect. Dis. 170, 743-744 (1994).

12. Lambert, I.S. et al. Safety and pharmacokinetics of hyperimmune anti-human immunodeficiency virus (HIV) immunoglobulin administered to HIV.infected pregnant women and their newborns. I. Infect. Dis. 175, 283-291 (1997).

13. Montefiori, D.C. et al. Neutralizing and infection-enhancing antibody responses to human immunodeficiency virus type 1 in long term non-progressors. 1. Infect. Dis. 173, 60-67 (1996).

14. Harrer, T. et al. Strong cytotoxic T cell and weak neutralizing antibody responses in a subset of persons with stable nonprogressing HIV type 1 infection. AIDS Res. Hum. Retroviruses 12, 585-592 (1996).

\section{ERRAT UM}

Editorial changes made in the Letter by Parren et al (Nature Medicine 3, 366-377 (1997)) after proofreading resulted in a series of references becoming misnumbered. The corrected version of the Letter can be obtained from Dennis Burton via e-mail (burton@scripps.edu). 